\title{
A Reward-based Active Learning Approach for Motivating and Engaging Students in a Large Classroom
}

\author{
Smitha V George ${ }^{1}$, Supreetha $\mathrm{R}^{2}$ \\ ${ }^{1}$ Department of Computer Science and Engineering, St \\ Joseph Engineering College, Mangaluru-575028 \\ ${ }^{2}$ Department of Computer Science and Engineering, St \\ Joseph Engineering College, Mangaluru-575028 \\ ${ }^{1}$ smithag@sjec.ac.in \\ supreethar@sjec.ac.in
}

\begin{abstract}
Student engagement activities in the teachinglearning process have shown drastic developments and have helped not only in the exchange of information among students but also in the creation of knowledge. Active learning activities in teaching will allow students to participate in the learning process by reflecting on what they have learned. This can also include students working cooperatively in pairs or groups.
\end{abstract}

Whether it is about understanding concepts from the lectures or the implementation of concept-related information from the textbooks, group activities are of great use, especially while handling large classes. Group activity like in-class teams helps students to exchange information among their peers.

The purpose of the activity is to motivate the students and keep them engaged for the entire session. The in-class group activity proposed here is a reward-based approach which was a major motivation for the students and the competitive spirit among the teams kept them engaged in noting down the points being discussed in class and gathering information throughout the session.

The students of the class showed a better understanding of the concepts and good performance during the assessment. This paper describes the effective deployment of active learning to enhance the attention span of the students and keep them engaged for the entire session and thereby provides effective Outcome-Based Education (OBE). The results show that the attainment of the students' performance is enhanced. Moreover, it improves team spirit and team performance through cooperative learning.

Keywords: Active learning, cooperative learning, student engagement, student motivation.

\section{Introduction}

"To teach is to engage students in learning." This quote, from Education for Judgment by Christensen et al. [1], captures the essence and practice of this activity of engagement which is the focus of this paper. It highlights the fact that engaging students in learning have become the principal responsibility of the teacher, who has now become not as much an imparter of knowledge but more a designer and facilitator of learning experiences and opportunities for the students.

The focus of this paper is mainly student engagement through a group activity. In large classrooms, the students are distracted quite easily. Hence it becomes the responsibility of the teacher to keep them engaged for the entire session. Group activities often come in handy in such scenarios, whether it is about understanding the concepts or implementing it, especially while handling large classes. It promotes student engagement as well as the exchange of information among them and hence results in improved learning.

Edgerton, in his white paper [2], goes on to cite four strands of pedagogical reform that are moving in the same broad direction: problem-based learning, collaborative learning, service learning, and undergraduate research. This paper looks at a class of pedagogies of engagement, namely, those that are classroom-based. We focus particularly on cooperative learning and problem-based learning

The purpose of the activity proposed here is to motivate the students and keep them engaged throughout the session. In this paper, we have proposed an in-class group activity which is a reward-based approach. The reward was a major motivation for the students. It also encouraged them to make a note of the topics being discussed in class and kept them engaged for the entire session.

\section{Literature Review}

Edgerton introduced the term "pedagogies of engagement" in his 2001 Education White Paper [2], where he reflected on the projects on higher education. He mentioned the core issue, in my view, is the mode of teaching and learning that is practiced. Learning 'about' things does not enable students to acquire the abilities and understanding they will need for the twenty-first century. We need new pedagogies of engagement that will turn out the kinds of resourceful, engaged citizens".

The publication called The Seven Principles for Good Practice in Undergraduate Education [3] also stressed the 
pedagogies of engagement. The principles speak of the fact that good practice encourages student-faculty contact, cooperation among students, and active learning.

The project titled 'The National Survey of Student Engagement' (NSSE) [4] deepens our understanding of how students perceive classroom-based learning, as an element of student engagement in their college education. Here the learning is organized around five benchmarks: a. Level of academic challenge b. Active and collaborative learning c. Student-faculty interaction, d. Enriching educational experiences: Learning opportunities inside and outside classroom e. Supportive campus environment: Students are motivated and satisfied at schools that actively promote learning and stimulate social interaction.

Astin's [5] large-scale co-relational study of what matters in college found that two environmental factors were by far the most predictive of positive change in academic development, personal development, and satisfaction of a student. The main factors - interaction among students and interaction between faculty along with the pedagogies of engagement and classroom-based practices affected the education outcomes more than any other environmental variables studied.

Pascarella and Terenzini also presented a summary of their research on the impact that college has on student development, further, it supports the importance of student engagement: "The greater the student's engagement or involvement in academic work, the greater is his or her level of knowledge acquisition and general cognitive development. If the level of involvement were determined by individual student motivation, interest, and ability, the above conclusion would be uninteresting as well as unsurprising. However, a substantial amount of evidence indicates that there are instructional and programmatic interventions that not only increase a student's active engagement in learning and academic work but also enhance knowledge acquisition and some dimensions of both cognitive and psychosocial change" [6].

The approach adopted here takes the essence of all the papers reviewed. The learning from here can be generalized and can be of use to academicians, researchers, and policymakers who seek to implement active learning to accomplish OBE in the engineering discipline.

\section{Overview}

In this section, we provide an overview of the various active learning techniques and classroom-based pedagogies of engagement that are used in classrooms for engineering education. In section 4 we provide the proposed methodology and its implementation. The paper concludes by presenting the effectiveness of this classroom-based group activity and the results in section 5 .

Active learning has been described as "instructional activities involving students in doing things and thinking about what they are doing" [7]. Several research studies confirm that student engagement activities promote the reinforcement and construction of new knowledge through discussion and active exchange of information [8]. Listed below are a few commonly used, in-class activities to keep the students engaged.

a. Polls: This is a very easy and effective strategy for getting quick feedback after completing a segment of teaching. It is easy to create and implement and it takes less than 5 minutes. The objective is to get immediate feedback about the content covered in the part/whole lecture.

b. Summarizing: A very simple and common activity which involves making students summarize the key take away from the part of the lecture just completed.

c. One Minute Paper: This is also a very effective and easy to implement activity and can be done in the beginning, middle, or towards the end of a lecture. The objective is to get quick feedback from the students. In this activity, students are asked to write on a piece of paper a few lines or points in bullet form as a response to a question. The solution or issue has to be discussed in the following session.

d. Think-Pair-Share: It is best used within the lecture when a concept/or part concept has been completed and the teacher wants to check how well the students have understood it. This activity is completed in three steps. The teacher starts by posing an application-based question: Each student is asked to think quietly about the response to the question. Students then pair up with the neighbor/s and discuss the same. The teacher then asks (randomly) the pairs/threesomes to give their responses.

e. Thinking Aloud Pair Problem Solving (TAPPS): The activity is designed to develop problem-solving skills through discussion and sharing of ideas. Here, partners construct a common contextual framework to understand the concept taught and they do it by jointly solving a given problem based on the concept. Here, Students are asked to work in pairs-one acting as the 'Solver" and the other as the "Inquirer". The problem solver reads the problem aloud and works out the solution in steps. The inquirer follows all and catches any errors/flaws and asks questions if any. Pairs are picked randomly to explain their solution. Next time the pairs work with the reversed roles of the 'Solver' and the Inquirer'.

f. Visible Quiz: In this activity, students are put in foursomes. A quiz type question is created with a multiple-choice response. Each team is given a set of large cards imprinted with one of the four letters indicating the options.

The group is given a specified time to discuss and arrive at an agreed solution. The teams are then asked to show their solutions.

g. Designing Questions: This is a way of assuring higherorder learning, it makes students formulate questions on the content studied. This activity can be done in pairs or threesomes. The instructor can then choose to prepare a question bank with the questions framed.

h. Problem-Solving Exercises: In this activity, a problem is presented and pairs or small groups are asked to provide the solution along with the steps.

i. Verbal quiz: Students love this activity and it is always very successful in motivating students. Create questions with 
different levels of difficulty (medium, /high) from the content studied in class. Divide the class into teams and pose the questions. Any member of the team can answer the question. If the answer is correct, the team gets 1 point -if the answer is wrong, they get a 0 , and the question passes to the next team. The team that scores the highest points wins. The activity is ideal for reinforcing difficult concepts and energizing the class.

j. Critical Thinking Exercise: Another very interesting and easy to implement the activity. Divide the class into small groups. A case study (refers to a failed project) is given to each group. The groups are asked to identify errors/deficiencies leading to the failure of the project. At the end of the stipulated time, the group is provided with the solution, and the groups are asked to assess their performance and give themselves a grade.

The model of the active-learning process in this paper is a variation of the verbal quiz activity mentioned above it is predicated on cooperation-working together to accomplish shared goals. Within such cooperative activities, individuals seek outcomes that are beneficial not only to themselves but also to other group members. It indicates the use of small groups so that students work together to maximize their learning experience as well as others. If cooperative learning activities are carefully structured it involves students working in teams to accomplish a common goal, with positive interdependence, and ensures each member individually as well as all members are collectively accountable for the work of the group.

\section{Proposed Methodology}

"A team is a small number of people with complementary skills who are committed to a common purpose, performance goals, and approach for which they hold themselves mutually accountable" [9].

We implemented cooperative learning where students were required to work together to achieve a joint learning goal in groups consisting of 4 members. The class consisted of 60 students. Hence, there were 15 groups in total. The students were asked to form the groups based on the order in which they were seated in the classroom during the lecture sessions. Once the groups were formed, they had to continue with the same members for the entire course, which spanned for 4 months. The reason for forming such Informal cooperative learning groups was to ensure that the team members were comfortable with each other and that they could cooperate and help each other in case of misconceptions, incorrect understanding, and gaps in understanding if any, thus ensuring personalized learning experiences.

Once the groups were formed, the teams were asked to select a suitable name for their team and also select a team leader. After the teams were ready, all the team names and the members of the respective teams were noted down.

The task mentioned above was carried out during the introductory session before the commencement of the course. The teams were given clear instructions as listed below:

- The teams have to stay alert during the lecture session and note down important points from the topics that would be discussed during the class.

- All members of the team have to actively participate and cooperate with each other to find answers to the questions posed or solve any given problem pertaining to the concept discussed.

- Every ten to fifteen minutes, or after the completion of a particular topic the lecture would be stopped and questions would be posed to the teams.

- Teams will be given 1-2 minutes to discuss with each other and find answers to the questions.

- The team which comes up with the answer or finds the solution first will be given 1 point.

- If multiple teams come up with the answers simultaneously, all of them will be given 1 point each.

- There will be negative marking for the teams whose members are noticed to be inactive or not involved in the discussions.

- The points gained by the teams will be carried forward for the subsequent sessions.

- At the end of the course, the team with maximum points will be given a reward.

After giving clear instructions, the course commenced. Each session of the course followed the pattern shown in Fig.1

\section{Book Ends on a Class Session}

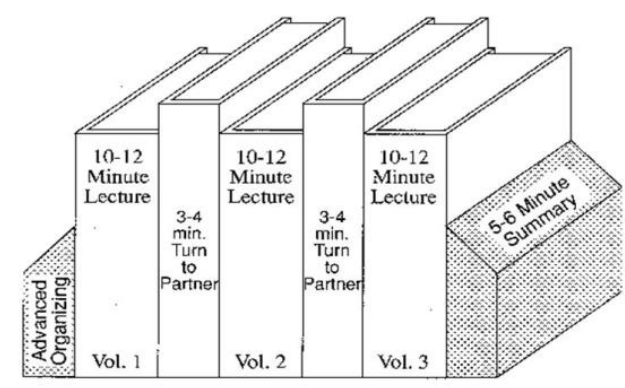

Fig.1 Bookends on a class session [10]

Breaking up lectures with short cooperative processing times resulted in reduced lecture time, but re-engaged the students. During lecturing and direct teaching, we ensured that students did the intellectual work of organizing material, summarizing, and integrating it into existing real-time situations. At the end of the course, the winning team and the runners up were presented with a small gift as promised. 


\section{Effectiveness and Results of Classroom Implementation}

At the end of the course, the students of the class showed a better understanding of the concepts and performed well during the assessment as compared to the previous semester. This activity describes the effective deployment of active learning to enhance the attention span of the students and keep them engaged for the entire session and thereby providing effective OBE. A survey was conducted at the end of the course which clearly showed that enhanced student performance has been achieved and the attainment of the outcome is also accomplished. The act of rewarding the team which scored the highest points was highly appreciated by the class and the winning team was overwhelmed to receive this token of appreciation from their faculty.

Apart from enhancing the learning experience and student performance, the activity was beneficial in following the terms:

i) Positive interdependence: The heart of this activity is positive interdependence. Students believed that they are linked with others in such a way that one could not succeed unless the other members of the group also succeed and vice versa. In other words, it created a realization among students that they would sink or swim together. In such cooperative learning groups, positive interdependence may be structured by asking the group leader to (1) agree on an answer for the group, (2) make sure that each member could explain the answer effectively, and (3) fulfill assigned role responsibilities.

ii) Promote Face-to-face interaction: The students interact to help each other accomplish the task and promote each other's success and thus the success of the team. It was observed that the members explained orally to each other how to solve problems, discussed the nature of the concepts and strategies being learned, shared their understanding with their team members, provided help, encouragement, and support to each other's efforts.

iii) Individual accountability/personal responsibility: This activity made each member a stronger individual in his or her own perspective. Students learned together so they can subsequently perform better as individuals. To ensure that each member is strengthened, students were held individually accountable for his/her share of the work. Even silent students who were initially not involved were encouraged to get involved eventually for the benefit of their team members and the team as a whole.

iv) Skill of Teamwork: Contributing to the success of cooperative learning activity was the teamwork skills, which included leadership skills, along with skills for decision making, trust-building, communication, and conflict management. Many students had no prior experience working cooperatively in learning groups and therefore lacked the necessary teamwork skills which were eventually developed through this activity. v) Group processing: As Faculty we discussed with each group how well they were performing and thus achieving their goals and maintaining effective working relationships. Groups were given feedback about what member actions were helpful and what was not, and thus encouraged team leaders in making decisions about what to continue or change. Such processing enabled learning groups to focus on group maintenance, facilitated the learning of collaborative skills, and reminded students to practice such skills consistently.

The graph in Fig 2 shows the benefits of the approach.

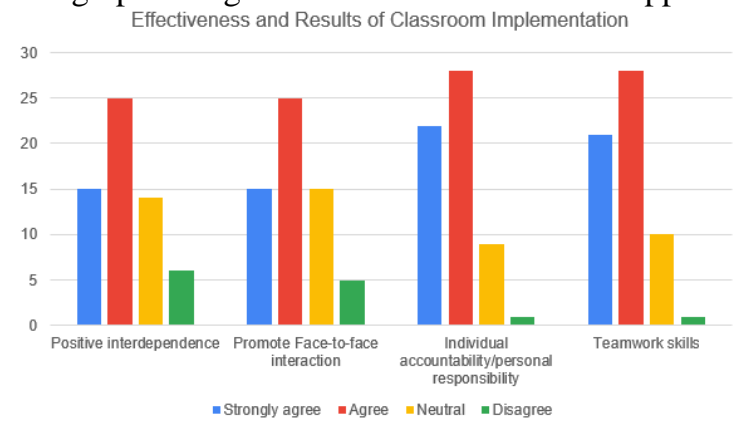

Fig 2 Effectiveness of the approach

The level of knowledge of the students on the subject before the commencement of the course was assessed through a quiz. A similar assessment was conducted towards the end of the course. There was a significant difference which is depicted in the graph shown in Fig. 3

\section{Contribution to learning}

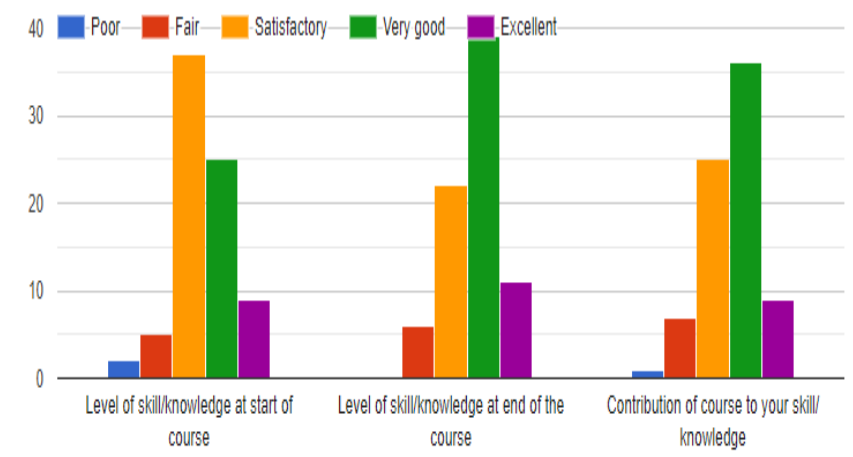

Fig.3 Contribution to Learning

\section{Conclusion}

We have observed that "The greater the student's engagement or involvement in academic work, the greater is his or her level of knowledge acquisition and general cognitive development". But it becomes practically impossible to involve every student in a large classroom, moreover, getting the attention of the entire class for the 
whole session becomes even more challenging in a large classroom. This reward-based approach becomes very useful in such scenarios. As the teams formed here remain the same for the entire course, a bond of understanding is developed among the team members which enables them to work together and cooperate with each other. Moreover, the teams who perform poorly during the initial sessions get sufficient time to improve and make up for the loss even later. The teams have to perform consistently well to emerge as winners towards the end of the course.

Thus we conclude that this is an effective approach for motivating and engaging students in a large classroom.

\section{References}

[1] Christensen, C.R., Garvin, D.A., and Sweet, A., Education for Judgment: The Artistry of Discussion Leadership, Cambridge, Mass.: Harvard Business School, 1991

[2] Edgerton, R., Education White Paper, 2001, http://www.pewundergradforum.org/wp1.html

[3] Chickering, A.W., and Gamson, Z.F., "Seven Principles for Good Practice in Higher Education," American Association for Higher Education Bulletin, Vol. 39, 1987, pp. 3-7.

[4] National Survey of Student Engagement: The College Student Report-2003 Annual Report, Bloomington, Ind.: Center for Postsecondary Research, Indiana University, 2003.

[5]Astin, A., What Matters in College? Four Critical Years Revisited, San Francisco, Cal.: Jossey-Bass, 1993.

[6]Pascarella, E.T., and Terenzini, P.T., How College Affects Students: Finding and Insights from Twenty Years of Research, San Francisco, Cal.: Jossey-Bass, 1991.

[7]Bonwel, Charles C; Eison, James A. Active Learning: Creating Excitement in the Classroom.191ASHE-ERIC Higher Education Reports.

[8]Bodner G. M., (1986), Constructivism: a theory of knowledge, J. Chem. Educ., 63, 873-878.

[9]Katzenbach, J.R., and Smith, D.K., The Wisdom of Teams: Creating the High-Performance Organization, Cambridge, Mass.: Harvard Business School Press, 1993.

[10] Karl A. Smith, Sheri D. Shepherd, David W. Johnson, Roger T. Johnson, Pedagogies of Engagement: ClassroomBased Practices, Journal of Engineering Education, 2005. 